\section{ASSISTÊNCIA SOCIAL PÚBLICA BRASILEIRA: UMA POLÍTICA DA AUTONOMIA - UM DISPOSITIVO BIOPOLÍTICO}

\author{
Public Brazilian Social Service: A Policy of Autonomy - A \\ Biopolitical Device
}
Asistencia Social Pública Brasileña: Una Política de la Autonomía - Un Dispositivo Biopolítico

\author{
Assistance Sociale Publique Brésilienne: Une Politique de \\ L'autonomie - Un Dispositif Biopolitique
}

\begin{abstract}
Resumo
O objetivo do presente artigo é evidenciar o caráter biopolítico da Política Nacional de Assistência Social/Sistema Único de Assistência Social (PNAS/SUAS), considerando a perspectiva de Michel Foucault sobre o exercício de poder acerca dos fenômenos da população, tais como natalidade, saúde, higiene, escolaridade etc. Assim, a PNAS/SUAS é analisada enquanto dispositivo, como uma configuração formada por discursos, leis, práticas, instituições, tecnologias e normas, com a função de promover a autonomia como condição de cidadania, atuando sobre os hábitos, condutas e vínculos familiares e comunitários dos indivíduos e famílias em situações de riscos e vulnerabilidades sociais. Aborda-se textos, pesquisas, orientações e dados referentes às ações, práticas e procedimentos técnicos operados pela Assistência, destacando-se inicialmente a mudança do estatuto ético e político do usuário do PNAS/SUAS, de indigente para sujeito de direito. Em seguida, se evidencia a promoção da autonomia como função estratégica do dispositivo assistencial, bem como a operacionalidade, através da qual os modos de vida dos indivíduos são redimensionados. A relevância e a contribuição desta pesquisa se apoia na aplicação do olhar foucaultiano sobre a PNAS/SUAS, tomando-a como objeto de uma análise genealógica da autonomia do sujeito. Conclui-se que a PNAS/SUAS, antes de ser uma política de emancipação do sujeito, pela instauração das condições de cidadania, é um dispositivo biopolítico de normalização das condutas dos indivíduos em observância ao imperativo da autonomia.
\end{abstract}

Palavras-chave: PNAS/SUAS; dispositivo biopolítico; autonomia; Foucault.

\section{Abstract}

The purpose of this article is to show the biopolitical character of the National Policy for Social Assistance / Unified System of Social Assistance (PNAS / SUAS), considering the perspective of Michel Foucault on the power exercise on population phenomena such as birth, health, health, education etc.. Thus, PNAS / SUAS is analyzed as a device, like a configuration formed by speeches, laws, practices, institutions, technologies and standards, with the function of promoting the autonomy as a condition of citizenship, acting on the habits, behaviors and family and community ties of individuals and families at risk and social vulnerability. Texts, research, guidelines and data relating to the actions, practices and technical procedures operated by assistance are addressed, highlighting initially the change the ethical and political statute of the PNAS / SUAS user, from pauper to subject of rights. Then it became clear the promotion of autonomy as a strategic function of the assistance device, as well as the operationality by which the lifestyles of individuals are

\section{Biopolítica e Subjetividades Contemporâneas}

\begin{abstract}
Virginia Serpa ${ }^{(1)}$
Clara Virgínia ${ }^{(2)}$ Sylvia Cavalcante ${ }^{(3)}$

1) Mestre em Psicologia Programa de Pós-Graduação em Psicologia da Universidade de Fortaleza - UNIFOR (2014) e graduação em Psicologia pela Universidade Federal do Ceará (2002).

2) Professora do Programa de PósGraduação em Psicologia da UNIFOR, doutorado em Saúde Coletiva pela Universidade do Estado do Rio de Janeiro (2002), pós-doutorado no CNRS/CERME3/ Université Paris-Descartes, mestrado em Psicologia pela Pontifícia Universidade Católica de Campinas (1992) e graduação em Psicologia, UFC (1986).
\end{abstract}

3) Doutora em Psicologia, professora do Programa de Pós-Graduação em Psicologia da UNIFOR. 
resized. The relevance and contribution of this research is based on the application of Foucault's look on the PNAS / SUAS, taking it as the object of a genealogical analysis of individual autonomy. We conclude that the PNAS / SUAS, before being an emancipation policy of the subject, by the introduction of citizenship conditions, is a biopolitical device standards of conduct of individuals in compliance with the imperative of autonomy.

Keywords: PNAS / SUAS; biopolitical device; autonomy; Foucault.

\section{Resumen}

El objetivo del presente artículo es evidenciar el carácter biopolitico de la Política Nacional de Asistencia Social/Sistema único de Asistencia Social (PNAS/SUAS), considerando la perspectiva de Michel Foucault sobre el ejercicio de poder acerca de los fenómenos de la población, tales como natalidad, salud, higiene, escolaridad etc. Así, la PNAS/SUAS es evaluada mientras dispositivo, como una configuración formada por discursos, leyes, prácticas, instituciones, tecnologías y normas, con función de promover la autonomía como condición de la ciudadanía, actuando sobre los hábitos, conductas y vínculos familiares y comunitarios de los individuos y familias en situación de riesgo y vulnerabilidad social. Se utilizaron textos, investigaciones, orientaciones y datos referentes a las acciones, prácticas y procedimientos técnicos operados por la Asistencia, resaltando inicialmente el cambio del estatuto ético y político del usuario del PNAS/SUAS, de indigente para sujeto de derecho. A continuación, se evidenció la promoción de la autonomía como función estratégica del dispositivo asistencial, así como la operacionalidad, por lo cual los modos de vida de los individuos son reajustados. La relevancia y la contribución de esta investigación se basan en la aplicación de la mirada foucaultiana acerca de la PNAS/SUAS, tomándola como objeto de un análisis genealógico de la autonomía del sujeto. Se concluye que la PNAS/SUAS, antes de ser una política de emancipación del sujeto, por la implementación de las condiciones de ciudadanía, es un dispositivo biopolítico de normalización de las conductas de los individuos en observancia al imperativo de la autonomía.

Palabras clave: PNAS/SUAS; dispositivo biopolítico; autonomía; foucault.

\section{Résumé}

L'objectif de cet article est évidencier le caractère biopolitique de la Politique Nationale d'Assistance Sociale/ Sistème Unique d'Assistance Sociale (PNAS/SUAS) en considérant la perspective de Michel Foucault à propos de l'exercice de pouvoir sur les phénomènes de la population, comme natalité, santé, higiène, scolarité etc. Ainsi, la PNAS/SUAS est analysée tandis q'un dispositif, comme une configuration formée par des discours, des lois, des pratiques, des institutions, des technologies et normes, à la fonction de causer l'autonomie comme condition de citoyenneté en influençant les habitudes, les conductes et les liens familiers et communautaires des individus et familles à la situation de risque et vulnérabilité sociale. On a abordé des textes, des recherches, des orientations et des données référentes aux actions, pratiques et procédures techniques réalisées par l'Assistance, en se détachant d'abord le changement du statut éthique et politique de l'utilisateur de la PNAS/SUAS, de l'indigent au sujet de droit. Ensuite, on a souligné la promotion de l'autonomie comme fonction stratégique $d u$ dispositif d'assistance et aussi l'opérabilité par laquelle les modes de vie des individus sont redimensionés. L'importance et la contibution de cette recherche se fait par l'aplication du regard foucaultien sur la PNAS/SUAS, em la prenant comme objet d'une analyse généalogique de l'autonomie du sujet. On conclut que la PNAS/SUAS, avant d'être une politique d'émancipation du sujet, par l'instauration des conditions de citoyenneté, est un dispositif biopolitique de normalisation des conduites des individus qui sont à l'observance de l'impératif de l'autonomie.

Mots-clés: PNAS/SUAS; dispositif biopolitique; autonomie; Foucault.

A assistência no Brasil como uma Política de Seguridade Social é uma prática recente, tendo como marco legal a Constituição de 1988, a regulamentação da Lei Orgânica da Assistência Social (LOAS) no ano de 1993 e a aprovação da Política Nacional de Assistência Social (PNAS) em 2004. A PNAS expressa a materialidade do conteúdo da Assistência Social e da LOAS, criando uma nova matriz para a assistência social, inserida no sistema de bem-estar social, compondo o tripé da seguridade social, juntamente com a previdência e a saúde.

Como política de Estado, a assistência social brasileira organiza-se em Proteção Social Básica (PSB) e Proteção Social Especial (PSE), que se distinguem pela função dos programas, serviços, ações e benefícios. As ações de proteção básica são de caráter preventivo, com vistas à diminuição das vulnerabilidades e riscos sociais, pautandose pelos direitos de cidadania. A assistência especial - PSB - diz respeito aos serviços oferecidos prioritariamente pelo Centro de Referência de Assistência Social (CRAS), unidade pública estatal de base territorial, que se localiza, em geral, em áreas de maior vulnerabilidade social. A PSE tem por objetivo oferecer serviços, programas, ações e benefícios de caráter protetivo, quando há iminência ou já ocorreu a violação de direitos.

Efetivamente, as responsabilidades e competências para a operacionalização da assistência - tais como os níveis e instrumentos de gestão, critérios de partilha e transferência de recursos, proteções a serem ofertadas - são divididas entre as três esferas de governo, federal, estadual e municipal, possibilitando a implementação de um Sistema 
Único de Assistência Social (SUAS). Portanto, a PNAS/ SUAS constitui uma rede de proteção social extensiva a todo território nacional.

Assim, queremos assinalar que a PNAS/SUAS é uma política que opera a assistência social em todo território nacional, como direito do cidadão e dever do Estado, configurando, então, um campo formado por leis, instituições, práticas, regras, normas e diretrizes operacionais, tecnologias, valores, discursos etc.; possui também a função estratégica de proteção social.

Ademais, a PNAS/SUAS é uma estratégia de produção de autonomia, pois as políticas públicas implicam a transformação do estatuto ético e político do beneficiário, da condição de miserável, alvo do assistencialismo e da caridade, para o de sujeito de direito. Tal estatuto assegura não somente que o indivíduo seja assistido em suas necessidades básicas, mas também na instauração das condições para o exercício da cidadania pela conquista da autonomia, pois a assistência

[...] opera com a provisão de necessidades humanas que começa com os direitos à alimentação, ao vestuário e ao abrigo, próprios à vida em sociedade. A conquista da autonomia na provisão dessas necessidades básicas é a orientação desta segurança da assistência social. (MDS, 2009, p. 10)

Desse modo, o indivíduo é apreendido pela assistência pública tendo em vista o desenvolvimento da autonomia como condição de cidadania. Então, podemos dizer que a PNAS/SUAS funciona como dispositivo de autonomia. Com efeito, a política de assistência social altera o estatuto político e social do indivíduo necessitado de ajuda, suprimindo a visão do usuário como miserável, alvo do assistencialismo e da caridade, para o de sujeito de direito.

Nosso questionamento versa, portanto, a respeito das instituições, discursos, valores, normas e medidas através do qual os modos de vida dos indivíduos são redimensionados em referência à autonomia. Por conseguinte, a PNAS/ SUAS é tomada como objeto de nossa investigação como um dispositivo político e tecnológico de produção da autonomia do indivíduo, considerando a seguinte definição de dispositivo, de acordo com Foucault (1997, p. 299):

Conjunto decididamente heterogêneo comportando os discursos, instituições, construções arquitetônicas, decisões regimentares, leis, medidas administrativas, enunciados científicos, proposições filosóficas, morais filantrópicas, logo: o dito, bem como o não-dito, eis os elementos do dispositivo. $\mathrm{O}$ dispositivo é propriamente a rede que se estabelece entre esses elementos.

Compreende-se, pois, que dispositivo diz respeito a uma configuração de elementos, com uma função estratégica, atuando sobre os indivíduos, seus hábitos e modos de vida e relações sociais. Como nos esclarece Agambem (2009, p.11), o dispositivo é o "conjunto das instituições, dos processos de subjetivação e das regras em que se concretizam as relações de poder".

Portanto, é como dispositivo que pomos em questão a PNAS/SUAS, com objetivo de evidenciar seu caráter de tecnologia política da autonomia, difundindo-a como norma de vida e expectativa social a propósito dos modos de vida dos indivíduos e das famílias. Portanto, é como dispositivo que pomos em questão a PNAS/SUAS, com objetivo de evidenciar seu modus operandi como política da autonomia, difundindo-a como norma de vida e expectativa social a propósito dos modos de vida dos indivíduos e das famílias.

Para isso, analisamos os textos e pesquisas referentes à Política Nacional de Assistência Social (PNAS-2004) e à Norma Operacional Básica (NOB/SUAS), disponibilizados pelo Ministério do Desenvolvimento Social e Combate à Fome; também examinamos os procedimentos técnicos operados na assistência a uma família numa unidade do CRAS situada num município cearense, cadastrada no Sistema Único de Assistência Social.

Neste material exploramos, no primeiro tópico, a mudança do estatuto social do usuário, de indigente para sujeito de direito, indicando transformações nas relações de poder implicadas nas práticas da assistência. Em seguida, no tópico II, evidenciamos a promoção da autonomia como a função estratégica do dispositivo assistencial pelo qual os modos de vida dos indivíduos e das famílias são redefinidos, bem como a operacionalidade das ações da política da autonomia.

Assim, para além de uma pesquisa sobre a gestão, organização e execução das ações de proteção social - tal como estudaram, por exemplo, Marco Aurélio Alcântara, Cristina Gladys Mingarelli Nogueira e Mariângela Ribeiro de Almeida e a equipe de pesquisadores da qual Salete da Dalté coordenadora ou, ainda, da pesquisa sobre os parâmetros para avaliação da política, tal como examinaram Marinho e Façanha (2001) sobre a eficiência e efetividade dos programas sociais - nós achamos que a investigação da PNAS/SUAS como um dispositivo ético/político, por meio da ferramenta conceitual foucaultiana abre um campo de visão pelo qual os discursos, leis, decisões, diretrizes, equipamentos, benefícios são vistos como um conjunto de elementos que atuam sobre as condutas dos indivíduos redimensionando-as em observância à norma da autonomia.

Trata-se de estudá-la como uma tecnologia através da qual a autonomia funciona como parâmetro de avaliação dos modos de viver dos indivíduos. Portanto, consideramos que a relevância e a contribuição desta pesquisa se referem à aplicação do olhar foucaultiano sobre PNAS/SUAS, tomando-a como objeto de uma análise genealógica da autonomia, como dispositivo biopolítico, quer dizer, como "[...] técnicas e procedimentos destinadas a 
dirigir a condutas dos homens" (Foucault, 1997, p. 101). Dessa maneira, salientamos a inovação epistemológica e metodológica da perspectiva foucaultiana, criando um ponto de vista sob a qual a assistência é analisada como uma tecnologia dos modos de subjetivação.

\section{Assistência Social como Direito do Cidadão e Dever do Estado: O Redimensionamento Ético e Político do Beneficiário da Pnas/Suas}

A análise da Política de Assistência Social requer, inicialmente, que situemos, mesmo de maneira breve, sua trajetória e particularidades históricas na sociedade brasileira. Com isso, pretendemos evidenciar a descontinuidade entre a caridade que se praticava no período que antecede a promulgação da Constituição de 1988 e a política assistencial que compõe juntamente com a saúde e a previdência o sistema de seguridade social, salientando, portanto, que a assistência enquanto política é algo recente. Queremos ressaltar as diferenças entre uma e outra no que diz respeito ao estatuto político-social do indivíduo demandatário da ajuda pública.

A assistência social, conforme a definição de Mestriner (2008), consiste em um conjunto de ações e atividades, público e/ou privado, com o objetivo de suprir, sanar ou prevenir, através de tecnologias específicas, as necessidades e carências dos indivíduos e/ou dos grupos, no que diz respeito à sobrevivência, convivência e autonomia social.

Com efeito, o auxílio ao outro necessitado é uma prática antiga, uma vez que em diferentes sociedades a solidariedade dirigida ao pobre, viajante, doente ou incapaz sempre esteve presente. Essa ajuda pautava-se na compreensão de que na humanidade sempre existirão os mais frágeis (Nozabielli, Lonardoni, Gimenes, \& Santos, 2006).

Daí, diferenciamos duas posições da prática assistencial. Na primeira, a assistência é exercida como caridade, dependente de iniciativas particulares, consistindo, portanto, em ações pontuais, fundadas no espírito cristão de amor ao próximo e na benemerência dos indivíduos. A ajuda é direcionada aos pobres, famintos, idosos, doentes, pessoas com deficiência, incapazes para o labor, enfim, a todos aqueles que suscitem misericórdia. Na segunda, a assistência é uma política de Estado. Como a caridade não é uma política de assistência, os socorros prestados aos necessitados não são orientados pela concepção da pobreza como um problema de desigualdade social, mas como desgraça pessoal, acontecimento natural. De acordo com Mestriner (2008), a pobreza é vista como algo que existe desde sempre, relacionado à má sorte, à doença, por exemplo, ou às falhas dos esforços do indivíduo para progredir na vida, mas não como uma problemática política. Sob a ótica assistencialista, o necessitado ao ser assistido torna-se devedor, da mesma forma que é devedor da bondade alheia, ao ser assistido por particulares, por instituições filantrópicas ou casas de caridade.

No Brasil, de acordo com Mestriner (2008), até 1930 a assistência social possuía um caráter eminentemente filantrópico e religioso. Em 1938, com a criação do Conselho Nacional de Serviço Social (CNSS), inicia-se um processo de regulação da prática assistencial, sem alterar, contudo, o caráter assistencialista de suas ações. Também, ainda como instituição filantrópica, foi criada em 1947 a Legião Brasileira de Assistência (LBA), com a função de prestar auxílio às populações necessitadas, através de ações pontuais, descontínuas e emergenciais.

A Constituição Federal de 1988 (CF/88) é o divisor de águas entre a caridade e a política de proteção social, que compreende "um conjunto integrado de ações de iniciativa dos Poderes Públicos e da sociedade, destinado a assegurar os direitos relativos à saúde, à previdência e à assistência social" (CF/88, art.194). Trata-se, então, da assistência como direito do cidadão e obrigação do Estado.

É a propósito do sujeito de direito que se instaura em 2004 a Política Nacional de Assistência Social (PNAS), executada pelo Sistema Único de Assistência Social (SUAS). Trata-se da mudança do estatuto ético e político do indivíduo necessitado, na medida em que este é deslocado de um lugar de exclusão social, como indigente, objeto da compaixão alheia, para o de cidadania, como sujeito de direito. Nesse novo campo jurídico, o indivíduo é assistido não só para atender às necessidades básicas, mas, também, para promover à aquisição da autonomia. Vejamos, então, a respeito da PNAS:

A nova concepção de assistência social como direito à proteção social, direito à seguridade social, tem duplo efeito: o de suprir sob dado padrão pré-definido um recebimento e o de desenvolver capacidades para maior autonomia. (MDS, 2009, pp. 15-16)

É, portanto, a propósito da problemática da renda e da autonomia que o indivíduo é tomado como objeto das políticas assistenciais como cidadão, isto é, como sujeito de direito.

\section{PNAS/SUAS: Uma Tecnologia da Autonomia}

Para a análise da PNAS/SUAS como uma política da autonomia, partimos de um questionamento sobre a forma pela qual o beneficiário é problematizado pelas práticas de assistência. Para explorar essa interrogação seguimos a seguinte apreciação: "A Assistência Social como política de proteção social [...] significa garantir a todos que dela necessitem, e sem contribuição prévia a provisão dessa proteção." (MDS, 2009, p. 10). 
Perguntamo-nos, portanto: se a assistência se constitui como política de proteção, direito do cidadão e obrigação do Estado, em que consiste essa proteção social?

Como ação de proteção, a assistência focaliza os riscos e as situações de vulnerabilidade aos quais os indivíduos estão sujeitos, pois é pela problemática do risco e da vulnerabilidade que os indivíduos, no dia a dia de suas vidas, são apreendidos pela política de proteção, observados em dois níveis pela política assistencial: no nível macro social, pelo índice de natalidade, pela morbidade e pelo IDH; e no micro, pelos hábitos de vida dos indivíduos e das famílias. A MDS (2009, p. 10) estabelece:

Tudo isso significa que a situação atual para construção da política pública de assistência social precisa levar em conta três vertentes de proteção social: as pessoas, as suas circunstâncias e dentre elas seu núcleo de apoio primeiro, isto é, a família. A proteção social exige a capacidade de maior aproximação possível do cotidiano da vida das pessoas, pois é nele que riscos, vulnerabilidades se constituem. (MDS, 2009, p. 10)

Com efeito, a proteção pública se estende a uma série de indivíduos, abordados em razão de certas situações, tais como: infância, adolescência, velhice, doença, deficiência, indigência, etnia (índio, por exemplo), dependência química etc. Vale salientar que o denominador comum entre esses indivíduos é a situação de vulnerabilidade, de risco de exclusão social, não remetendo, portanto, somente à privação, mas também à marginalização, decorrente do ciclo vital, das condições de pobreza, da etnia, doença, deficiência etc. A exclusão é um problema social, na medida em que todos têm direito à cidadania.

Por isso, o risco e a vulnerabilidade se constituem em problemas sociais cruciais, que devem ser combatidos através de ações de socialização; não somente pela provisão, mas também pelo desenvolvimento das condições de autonomia. Uma prática assistencial pautada pela garantia dos direitos só poderia estar:

Aliada ao desenvolvimento humano e social e não tuteladora ou assistencialista, ou ainda, tão só provedora de necessidades ou vulnerabilidades sociais. O desenvolvimento depende também de capacidade de acesso, vale dizer de redistribuição, ou melhor, distribuição dos acessos a bens e recursos, isto implica incremento das capacidades de famílias e indivíduos. (MDS, 2009, p. 16)

Dessa maneira, podemos dizer que a função estratégica do dispositivo da assistência é o desenvolvimento das capacidades individuais para promover a autonomia. Assim, a propósito da autonomia o indivíduo é instado a ser empreendedor de si mesmo, como analisa Ehrenberg
(2010) em seu livro O Culto da Performance: Da aventura empreendedora à depressão nervosa. A ideia de triunfo, de excelência, de qualidade total, engendra a busca da perfeição e da superação de si próprio (Ehrenberg, 1998). Neste cenário, destacam-se os valores de inserção, de carreira, de poder e de qualificação social. A autonomia surge como uma norma, (Ehrenberg, 2004) nas palavras do autor:

[...] a autonomia é um elemento a partir do qual somos medidos, como o era antes a disciplina. Não se tem que tomar a autonomia por uma substância, uma realidade; é uma linguagem, e como tal, é alguma coisa normativa, que implica expectativas. (Ehrenberg, 2004, p. 153)

Essa função da política assistencial de desenvolver o potencial e as capacidade dos indivíduos e das famílias remete também ao sociólogo indiano Amartya Sen (2000, 2001), para quem a pobreza apresenta duas dimensões dissociadas: uma que diz respeito à baixa renda, à ausência de recursos básicos para a sobrevivência, a propósito da qual se definem programas de transferência de renda; outra que se refere ao precário desenvolvimento das capacidades individuais acerca da qual se impõem intervenções para capacitação. Para o autor, a política assistencial deve privilegiar e priorizar o desenvolvimento das capacidades para que o indivíduo se torne autônomo, provedor de suas próprias necessidades, "agentes livres e sustentáveis" (Sen, 2000, p. 170).

Capacidade, para Sen $(2000,2001)$, significa a condição necessária para que o indivíduo exerça, por conta própria, os atos que a vida lhe impõe, a propósito dos quais deve estar habilitado. Eis que "pobreza deve ser vista como privação de capacidades básicas em vez de meramente como baixo nível de renda, que é o critério tradicional de identificação da pobreza" (Sen, 2000, p. 109).

Portanto, o combate contra a pobreza implica apostar no desenvolvimento das capacidades básicas para que os indivíduos se tornem sujeitos autônomos, quer dizer, capazes de agir por si mesmos, tendo o Estado o dever de garantir as condições necessárias para tal conquista. Eis, então, a autonomia como parâmetro ético e político a propósito do qual os modos de vida do indivíduo são avaliados/julgados e redefinidos.

Importante é saber como a PNAS/SUAS opera como dispositivo da autonomia acerca dos modos de viver de seus usuários.

É através do SUAS que essa política "comprometida com o desenvolvimento humano e social do país" (MDS, 2009, p. 81) se realiza, organizando "serviços e ações integradas para o desenvolvimento da autonomia do sujeito" (MDS, 2009, p. 88). Assim, no domínio da assistência, o CRAS é a unidade de serviço assistencial, localizado nos mais diversos territórios brasileiros, que, através do Serviço de Proteção e Atendimento Integral à Família (PAIF), visa 
potencializar o protagonismo e a "autonomia individual, familiar e social” (MDS, 2009, p. 18).

Observa-se aí os dois aspectos constitutivos de um dispositivo, quais sejam: um conjunto de elementos interligados e uma função estratégica para alcançar um determinado fim. O dispositivo PNAS/SUAS é formado por lei, resolução, instituições, discursos, regras, programas, serviços, equipamentos e técnicas reunidos pela função de proteger e desenvolver capacidades para a autonomia como direito de cidadania. Assim, trata-se de um dispositivo uma vez que, tal como examinou Agambem (2009, p. 25), "parece se referir à disposição de uma série de práticas e de mecanismos (ao mesmo tempo linguísticos e não linguísticos, jurídicos, técnicos e militares) com o objetivo de fazer frente a uma urgência e obter um efeito".

Pois bem, a Assistência como uma Política Nacional de Assistência Social é instituída no campo da Seguridade Social como direito de cidadania e dever do Estado, "considerando o disposto no artigo 18, incisos I, II, IV, da Lei 8.742 de 7 de dezembro de 1993. A Lei Orgânica de Assistência Social (LOAS) estabelece a universalidade, a dignidade e a autonomia como princípios fundamentais da assistência como uma política de proteção social.

Assim, trata-se do direito de "quem, quantos, quais e onde estão os brasileiros demandatários de serviços e atenções de assistência social" (MDS, 2009, p. 10). Ademais, é a propósito das condições de cidadania que os indivíduos são apreendidos pelo dispositivo assistencial.

Situemos, então, a questão de saber sobre os parâmetros pelos quais os indivíduos e famílias se tornam usuários da assistência, tendo em vista a problemática da cidadania e da autonomia.

Com efeito, as famílias e indivíduos são detectados pelos radares da assistência social pelos indicadores de riscos e vulnerabilidades, quais sejam:

Famílias e indivíduos com perda ou fragilidade de vínculos de afetividade, pertencimento e sociabilidade; ciclos de vida; identidades estigmatizadas em termos étnico, cultural e sexual; desvantagem pessoal resultante de deficiências; exclusão pela pobreza e, ou, no acesso às demais políticas públicas; uso de substâncias psicoativas; diferentes formas de violência advinda do núcleo familiar, grupos e indivíduos; inserção precária ou não inserção no mercado de trabalho formal e informal; estratégias de alternativas diferenciadas de sobrevivência que podem representar risco pessoal e social. (MDS, 2009, p. 27)

Daí, queremos assinalar mais uma vez: são situações nas quais o que está em jogo é a questão da integração social, situando a exclusão social como problemática central das práticas assistenciais.

Essa problematização da exclusão social deve-se a uma "visão social inovadora [...], pautada na dimensão ética de incluir "os invisíveis", os transformados em casos individuais, enquanto de fato são parte de uma situação coletiva" (MDS, 2009, p. 10).

Assim, os riscos e vulnerabilidades dizem respeito às condições de exclusão social dos indivíduos e das famílias, como pobreza, desemprego, deficiência, velhice etc. Ademais, a sociedade é tomada como a realidade própria da exclusão social.

Efetivamente, as situações de vulnerabilidade, conforme o Atlas da Vulnerabilidade Social nos Municípios Brasileiros (Costa \& Marguti, 2015), referem-se a condições precárias de infraestrutura, desenvolvimento humano, renda e trabalho, que acarretam a fragilização dos vínculos afetivos e comunitários, tais como o analfabetismo e desqualificação profissional.

Por conseguinte, são pelos indicadores de vulnerabilidade que os indivíduos e as famílias são apreendidos pelo dispositivo assistencial, no qual os mais diversos aspectos dos modos de vida são avaliados: moradia, saneamento, natalidade, mortalidade, segurança, escolaridade, renda, trabalho etc.

Assim, as famílias e indivíduos ingressam na política da assistência através do CRAS, onde são acolhidos por profissionais de nível superior (na maioria, assistentes sociais, mas também psicólogos e pedagogos) que ouvirão as demandas e avaliarão as condições socioeconômicas e pessoais, visando os indicadores de riscos e vulnerabilidades. Além de outros possíveis encaminhamentos, as famílias e os indivíduos com o perfil de renda serão orientados a se inscreverem no Cadastro Único para Programas Sociais (CadÚnico).

Essa é a ferramenta de identificação e informação a respeito dos indivíduos e famílias em situação de risco e vulnerabilidade. Somente a partir da inscrição no CadÚnico é que o usuário passa a ter a acesso a uma série de benefícios, programas e projetos, como o Programa Bolsa Família, no qual, para ser beneficiária, além do registro no CadÚnico, a família deve ter uma renda no limite da extrema pobreza. Além dessa condição, o benefício depende da cota disponibilizada pelo governo federal para o município onde reside. Assim, pode ocorrer do usuário ter o perfil para gozar do benefício, no entanto ficar fora, devido ao número restrito de Bolsas. Esse fato é bastante criticado por Zimmermann (2009), que vê nisso o descumprimento do princípio de universalidade, disposto na LOAS, na medida em que muitas das pessoas em situação de risco e vulnerabilidade não são assistidas pela rede de proteção do Estado.

Os beneficiários dos programas de transferência de renda, dentre eles, aqueles que fazem jus ao Programa de Bolsa Família, devem cumprir as condições estabelecidas para a permanência no Programa, tais como os cuidados com a saúde e com a educação escolar e profissionalizante dos membros das famílias. Este aspecto é bastante criticado por alguns outros autores, como Silva, Yazbek e Giovanni 
(2007), pois afirmam que um direito não tem contrapartidas, imposições, exigências ou condicionalidades. As exigências e condicionalidades destituem o caráter de direito social dos programas, ameaçando os princípios de cidadania.

No entanto, não devemos esquecer que, para além da função de provisão das necessidades básicas, a assistência social visa fundamentalmente "desenvolver capacidades para maior autonomia" (MDS, 2009, p. 10). Assim, a assistência social tem um caráter normativo, na medida em que condiciona o ganho do benefício ao desenvolvimento do usuário, escolarização e/ou habilitação técnica. É como uma política da autonomia que a prática assistencial perde seu caráter assistencialista.

Trata-se aí de uma prática de proteção social básica, que visa "prevenir situações de risco por meio do desenvolvimento de potencialidades e aquisições [...]" (MDS, 2009, p. 27) necessárias para o exercício da autonomia, quer dizer, para que o indivíduo possa agir por si mesmo. Portanto, "aprender a pescar", expressão utilizada por Vianna (2001) referindo-se ao desenvolvimento das capacidades e potencialidades, é uma questão de direito do cidadão e obrigação do Estado.

Daí a proposição de serviços, programas e projetos para o desenvolvimento do usuário do PNAS/SUAS, como o Programa de Proteção e Atendimento Integral à Família (PAIF), o Programa Bolsa Família, o Programa Nacional de Acessos ao Ensino Técnico e Profissionalizante (PRONATEC), o Projeto Primeiros Passos, o Projeto Investimento Cidadão, entre outros.

O PAIF é o principal programa do CRAS, cujo objetivo, é a promoção de aquisições sociais e materiais, potencializando o protagonismo e a autonomia dos sujeitos, bem como fortalecendo a função protetiva das famílias assistidas (MDS, 2009).

Considerando, então, a Assistência como um dispositivo político para promoção da autonomia, como questão de cidadania, situamos a questão de saber como opera a assistência pública. Para isso, pomos em foco o itinerário de uma família cadastrada na rede pública de assistência social.

\section{Dona Maria}

A propósito do sistema operacional da PNAS/ SUAS, descrevemos o itinerário de uma família usuária da assistência social, atendida em uma unidade do CRAS localizado em um município cearense. Nosso objetivo é ilustrar alguns aspectos em jogo na operação contra o risco e a vulnerabilidade social. Além disso, focalizamos especificamente os procedimentos técnicos a propósito da assistência a uma família em situação de risco e vulnerabilidade com vistas ao desenvolvimento da autonomia. Os dados discutidos foram retirados do prontuário de atendimento da família, do relatório anual/2013 do CRAS investigado, bem como do Cadastro Único para Programas Sociais (CadÚnico).

Dentre tantas outras Marias demandatárias de ajuda pública, escolhemos Maria da Silva (nome fictício), 39 anos, 4 filhos, um marido alcoolista e um pai inválido.

Como tantos outros da mesma localidade - 8.989 famílias das 11.356 famílias cadastradas no CRAS - dona Maria não sabe ler nem escrever, habita com a família numa casa de tijolos e chão batido, três cômodos, um banheiro, sem esgoto, com água e energia provenientes de ligações clandestinas. Coleta, juntamente com os filhos, material reciclável no aterro sanitário do município, possui uma renda per capita de $\mathrm{R} \$ 55,00$ por mês. Os filhos de dona Maria, Luana, de 20 anos, Tereza, 16, Francisco, 15 e Severino, 4 anos, não frequentam a escola. Estão envolvidos com álcool e drogas, e tanto Tereza quanto a namorada de Francisco apresentaram gravidez precoce.

Portanto, a situação de vulnerabilidade da família Silva é indicada por vários fatores referentes às condições de moradia, trabalho e renda, conforme a definição do Atlas da Vulnerabilidade (Costa \& Marguti, 2015).

Diante disso, levando-se em conta os objetivos da proteção social básica de assistir aos usuários por meio "do desenvolvimento de potencialidades e aquisições e o fortalecimento de vínculos familiares e comunitários" (MDS, 2009, p. 27), foram dados os seguintes encaminhamentos para a família da dona Maria: os filhos foram direcionados ao Centro de Referência Especializado da Assistência Social (CREAS) e inseridos no Programa de Erradicação do Trabalho Infantil (PETI); a namorada do filho, grávida, de 14 anos, foi posta em umgrupo de grávidas para recebimento do kit maternidade e inscrita no Programa Nacional de Inclusão de Jovens (PROJOVEM); dona Maria foi direcionada para um curso profissionalizante de corte e costura; além de solicitações de cestas básicas e fraldas geriátricas para seu pai.

Ademais, na medida em que a política de assistência concede as famílias um benefício financeiro, embora insuficiente, insere-as no Programa de Atenção Integral a Família (PAIF), através do qual elas terão acesso a grupos de convivência, refeições diárias (sem custos) por até seis meses, renováveis, cursos, documentos de identificação, isenção na conta de energia elétrica, escola para seus filhos e posto de saúde. Neste programa a família é acompanhada por um profissional de nível superior que procura dar o suporte necessário para a superação da vulnerabilidade pelo desenvolvimento das capacidades e potencialidades.

Daí porque o recebimento desses benefícios envolve a exigência de que a família modifique seus hábitos e os modos de vida, de maneira que a criança e os adolescentes comecem a frequentar a escola e os equipamentos esportivos e culturais do município e, ainda, que dona Maria se qualifique profissionalmente. 
Com efeito, essas condicionalidades estão relacionadas à aposta no desenvolvimento das condições para uma vida autônoma como estratégia de inclusão e bem-estar social. Daí porque a obrigatoriedade do autoaprimoramento, escolarização e profissionalização. No entanto, a precariedade dos serviços oferecidos compromete o êxito das ações, posto que:

Observadas as carências no sistema público no provimento do ensino básico e da saúde pública, essa condicionalidade pode estabelecer uma relação de nãoequivalência no contrato entre os cidadãos e o Estado, já que ele subsidia a demanda com um desequilíbrio da oferta (qualidade) dos serviços básicos. Obriga o cidadão ao que ele não pode cumprir plenamente, pela própria deficiência institucional. (Ivo, 2008, p. 196)

As crianças de dona Maria, mas também da maioria das famílias, mesmo matriculadas na escola faltam às aulas para trabalharem ou mendigarem ou, simplesmente, se recusam a estudar, fato este que leva a sanções do benefício.

Conforme dados do relatório, apenas no ano de 2013, há 724 famílias em descumprimento das condicionalidades, considerando que temos 2051 famílias beneficiárias do Bolsa Família no território do CRAS do Município avaliado. Este número corresponde a mais de $35 \%$ das famílias cadastradas no Bolsa Família, o que é um número alto visto que nem todas as famílias possuem crianças ou adolescentes.

Com relação à condicionalidade da saúde, por inúmeras vezes, as famílias procuram o CRAS para reclamarem por não conseguir um acompanhamento sistemático no posto de saúde e acabam recebendo sanções por não cumprirem com o 'contrato' exigido, devido a um serviço que o próprio sistema de saúde não foi capaz de realizar. Esse fato repetiuse durante todos os sete anos em que estivemos trabalhando no município estudado, mas as dificuldades com os serviços de saúde certamente não se restringem a esse município este é um problema nacional.

Assim, os precários serviços públicos, inclusive aqueles referentes à Assistência Social, da qual, se tomarmos como exemplo o CRAS estudado - é importante frisar que o CRAS deste município é reconhecido nacionalmente pelo "bom" serviço que presta, servindo mesmo de modelo para outros municípios -, trabalha com um número de profissionais muito abaixo do necessário. Considerando apenas as famílias cadastradas no CRAS pesquisado, são 11.356 pessoas que devem ser acompanhadas por apenas quatro profissionais de nível superior. A estrutura física do local onde funciona o serviço encontra-se em péssimas condições e existe falta recorrente de provisão para a concessão dos eventuais benefícios - cesta básica, kit natalidade, fraldas etc. -, assim como de material de expediente. Desse modo, parece-nos uma tarefa difícil, talvez até inviável, o desenvolvimento das capacidades para a aquisição de uma vida autônoma.

\section{Considerações Finais}

A análise da política pública social de assistência enquanto dispositivo de autonomia demonstrou há um longo caminho a ser trilhado para que os objetivos da PNAS/ SUAS se realizem nos modos de vida de seus beneficiários. $\mathrm{O}$ alcance do seu objetivo "de desenvolver capacidades para maior autonomia" (MDS, 2006, pp. 15-16), não ocorre em plenitude, seja pela sua ainda sofrida estrutura física, parcos recursos ou problemas com seus operadores, seja pelos precários serviços prestados pelas outras políticas, tais quais saúde, educação e habitação, das quais depende para que seu trabalho se concretize, seja por sua própria concepção de pobreza, que se centraliza na renda e, no entanto, não a transfere de forma suficiente para que possa romper com o caráter assistencialista.

Como vimos, a inclusão social, resultante da emancipação e do desenvolvimento das famílias e da superação da situação de vulnerabilidade, ainda não é o retrato de nossa realidade.

Dessa forma, a transferência de renda, em especial no Programa Bolsa Família, mantém uma situação de "reprodução e controle da pobreza" (Silva, 2008), não possibilita a autonomia das famílias atendidas e não é capaz de "alterar as relações sociais vigentes, de enormes desigualdades, reproduzindo uma massa de trabalhadores mantidos na esfera do autoconsumo e da necessidade" (Ivo, 2008, p. 240).

Além disso, essa forma de se compreender e trabalhar a autonomia dos usuários da política de assistência responsabiliza-os e a suas famílias pela superação ou não de sua condição de vulnerável, uma vez que supostamente foilhes concedido todo o suporte para o desenvolvimento de sua autonomia, obrigando-os a ser autônomo. Os trabalhos de Ehrenberg (2010) destacam a grande responsabilidade e obrigatoriedade contemporânea que pesa sobre os indivíduos de serem autônomos. Segundo o autor eles se veem impelidos à autonomia, porém nem sempre dispondo dos meios suficientes para realmente efetivá-la. É exatamente essa realidade na qual se encontra grande parte da população brasileira, pois a pobreza, o baixo nível de escolaridade, o desemprego e a exclusão social são dificultadores do alcance da autonomia pelo sujeito. A Assistência Social, em forma de política na PNAS, tem a pretensão de promover e ofertar minimamente o que falta para que esse indivíduo possa, por ele próprio, produzir-se, criar-se e desenvolver sua autonomia e sair da situação de vulnerabilidade social na qual se encontra. Mas diante de serviços de péssima qualidade e da falta de recursos para políticas tão essenciais como saúde, educação e segurança 
o ideal de autonomia pode passar a ser quase inatingível.

A autonomia está ligada a possibilidades de escolhas, mas para tanto é necessário que as condições mínimas de existência - alimentação, moradia, saúde e educação estejam presentes e que a transferência de renda oferecida não esteja tão abaixo do mínimo necessário à sobrevivência. A autonomia seria possibilidade de liberdade, possibilidade de fazer escolhas dentro desse sistema de proteção social.

Ademais, para além da problemática da efetividade e dos êxitos das ações assistenciais como tecnologia da autonomia, ainda é importante que se evidencie, em conclusão, o caráter biopolítico das ações da PNAS/SUAS.

Como um dispositivo biopolítico, trata-se de entender a PNAS/SUAS como um conjunto de "procedimentos e meios utilizados para assegurar, numa sociedade dada, o 'governo dos homens"' (Foucault, 1997, p. 81), governo entendido como "atividade de direção dos indivíduos ao longo de suas vidas, colocando-os sob a autoridade de um guia responsável por aquilo que fazem e lhes acontece" (Foucault, 1997, p. 81).

A gênese e forma do poder como "governo dos homens" foi referido por Foucault (1997) à pastoral cristã, herdada da cultura hebraica, considerando as seguintes características: 1) trata-se da prática de um pastor que cuida e direciona o seu rebanho, que pode ser de ovelhas, mas também de homens, em suas travessias e deslocamentos; 2) sua função não é só garantir a subsistência do rebanho mas também dirigi-lo para um determinado fim; e, por último, 3) o rebanho deve ser cuidado como um todo, da mesma forma que cada um individualmente.

Ora, o PAIF, enquanto programa de acompanhamento integral às famílias, atuando no dia a dia dos espaços domésticos, visando a superação das situações de vulnerabilidades sociais, como habitação, transporte, trabalho, saúde, escolaridade, para o exercício da cidadania e da autonomia dos sujeitos implicados, pode ser entendido como uma estratégia de governo. Trata-se de uma tecnologia de normalização das formas de agir e viver dos indivíduos em conformidades com o padrão de autonomia.

Com efeito, a PNAS/SUAS é um dispositivo de poder a partir do qual "o conhecimento e o desenvolvimento das forças de um Estado" constitui seu fim último. É sob a ideia de Estado como realidade biopolítica, com seus próprios fenômenos e regularidades irredutíveis às "leis naturais ou divinas" (Foucault, 1994, p. 648), que os homens devem ser governados como parte de uma população, com vistas ao crescimento de suas forças, ao aumento de suas riquezas. Assim, a população é tomada como "fim e instrumento do exercício do poder de normalização das formas de vida dos indivíduos em observância ao imperativo da autonomia, com vistas ao fortalecimento da força do Estado" (Foucault, 1994, p. 648).

Ora, a saúde, escolaridade, qualificação profissional e a educação de dona Maria e de seus filhos só se tornaram alvos das políticas públicas de assistência social, na medida em que a família "Da Silva" é parte da população brasileira, cuja dinâmica, regularidades, vulnerabilidades, potencialidades se constituem como realidade biopolítica.

Portanto, considerando a perspectiva biopolítica foucaultiana, podemos concluir também nossa análise dizendo que antes de ser uma política de emancipação do indivíduo pela instauração de condições para conquista de uma vida autônoma, a PNAS/SUAS é uma política de assujeitamento, de normalização dos modos de vida dos indivíduos pela autonomia.

\section{Referências}

Agambem, G. (2009). O quê é um dispositivo? In V. N. Honesko (Trad.), O quê é o contemporâneo? E outros ensaios (pp. 25-51). Chapecó, SC: Argos.

Cadernos de Estudos Desenvolvimento Social em Debate, 16. (2014). Síntese das pesquisas de avaliação de programas sociais do MDS 2011-2014. Brasília, DF: Ministério do Desenvolvimento Social e Combate à Fome; Secretaria de Avaliação e Gestão da Informação.

Constituição da República Federativa do Brasil de 1988. (1988, 5 de outubro). Brasília: Casa Civil da Presidência da República.

Costa, M. A., \& Marguti, B. O. (2015). Atlas da vulnerabilidade social nos municípios brasileiros. Brasília: IPEA.

Ehrenberg, A. (2004). Depressão, doença da autonomia? Entrevista de Alain Ehrenberg a Michel Botbol. Ágora: Estudos em Teoria Psicanalítica, 7(1), 143-153. https:// dx.doi.org/10.1590/S1516-14982004000100009

Ehrenberg, A. (2010). O culto da performance: Da aventura empreendedora à depressão nervosa (P. F. Bendassolli, Org. e Trad.). São Paulo: Ideias e Letras.

Foucault, M. (1994). La gouvernementalité. In Ditsetécrits III (pp. 635-657). Paris: Gallimard.

Foucault, M. (1997). Segurança, território e população. In A. Daher (Trad), Resumo dos cursos do Collége de France (1970-1982) (pp. 79-86). Rio de Janeiro: Jorge Zahar Ed.

Ivo, A. B. L. (2008). Viver por um fio: Pobreza e política social. São Paulo: Annablume; Salvador: UFH/ UFBA. 
Marinho, A., \& Façanha, L. O. (2000). Programas sociais: Efetividade, eficiência e eficácia como dimensões operacionais. IPEA.

Mestriner, M. L. (2008). O Estado entre a filantropia e a assistência social (3a ed.). São Paulo: Cortez.

Ministério do Desenvolvimento Social e Combate à Fome. (2006). Secretaria Nacional de Assistência Social. Norma Operacional Básica de Recursos Humanos do Sistema Único de Assistência Social (NOB-RH/SUAS). Brasília, DF: Secretaria Nacional de Assistência Social.

Ministério do Desenvolvimento Social e Combate à Fome. (2009, Maio). Secretaria Nacional de Assistência Social. Política Nacional de Assistência Social PNAS/ 2004. Norma Operacional Básica NOB/SUAS. Brasília, DF: Secretaria Nacional de Assistência Social.

Nozabielli, S.R., Lonardoni, L., Gimenes, J. G., \& Santos, M. L. (2006). O processo de afirmação da assistência social como política social. Serviço Social em Revista, $8(2)$.

Sen, A. K. (2000). Desenvolvimento como liberdade. São Paulo: Companhia das Letras.

Sen, A. K. (2001). Desigualdade reexaminada. Rio de Janeiro; São Paulo: Record.

Silva, M. O., Yazbek, M. C., \& Giovanni, G. (2007). A política social brasileira no século XXI: A prevalência dos programas de transferência de renda ( $3^{\text {a }}$ ed.). São Paulo: Cortez.

Silva, M. O. (Coord.) (2008). O bolsa família no enfrentamento à pobreza no Piauí e no Maranhão. São Paulo: Cortez; Teresina: Ed. Gráfica da UFPI.

Vianna, M. L. T. W. (2001). As armas secretas que abateram a Seguridade Social. In I. Lesbaupin (Org.), O desmonte da nação (pp. 91-114). Petrópolis, RJ: Vozes.

Yazbek, M. C. (2004). As ambiguidades da Assistência Social brasileira após 10 anos de LOAS. Serviço Social e Sociedade, 77, 22- 47.

Zimmermann, C. R. (2009). As politicas sociais e os direitos: Alguns apontamentos sobre o Programa Bolsa Familia no Nordeste. Retirado de http://xivciso. kinghost.net/artigos/Artigo_1295.pdf
Endereço para correspondência:

Virginia Serpa

Endereço: Rua Alcantaras, no 220, Bairro de Fátima.

Fortaleza/CE, CEP: 60055-350.

E-mail: viviserpa17@hotmail.com

\section{Endereço para correspondência:}

Clara Virgínia

Endereço: Av. Washington Soares, n 321, Bloco N, sala 13, Bairro Edson Queiroz. Fortaleza/CE, CEP: 60811-905. E-mail: claravirginia@unifor.br

\section{Endereço para correspondência:}

Sylvia Cavalcante

Endereço: Av. Washington Soares, n 321, Bloco N, sala 13, Bairro Edson Queiroz. Fortaleza/CE, CEP: 60811-905. E-mail: sylviac@unifor.br; sylviac91@gmail.com 